\title{
Effect of Starch Addition in Alkaline Electrolyte on the Characteristics of Plasma Electrolytic Oxidation Coating on AZ31B Mg Alloy
}

Yinyu Fang, Xiaohua Tu*, Chengping Miao, Yaling Xu, Wei Xie, Fangda Chen, Yang Zhang, Jiayou Li

College of Biological and Chemical Engineering, Jiaxing University, Zhejiang, Jiaxing 314001, China

*E-mail: tuxiaohua@mail.zjxu.edu.cn

doi: $10.20964 / 2017.12 .17$

Received: 12 September 2017 / Accepted: 17 October 2017 / Published: 12 November 2017

The oxide coatings were produced on AZ31B Mg alloy using plasma electrolytic oxidation (PEO) process in alkaline electrolyte with and without addition of starch. The properties and surface morphologies of the PEO coatings were studied by voltage-time curves, scanning electron microscopy (SEM), X-ray diffraction (XRD) and potentiodynamic polarization, respectively. It was found that the coating formed in the electrolyte with starch has more compact and uniform morphology than that formed in the electrolyte without starch. The XRD analysis showed that the compositions of coatings formed in the electrolytes with and without starch are almost the same, containing $\mathrm{MgO}$, $\mathrm{MgSiO}_{3}$, and $\mathrm{Mg}_{2} \mathrm{SiO}_{4}$. The results of potentiodynamic polarization tests showed that the coating formed in the electrolyte with starch enhanced the anti-corrosion characteristic.

Keywords: Mg alloy, coating, oxidation, starch, corrosion

\section{FULL TEXT}

(C) 2017 The Authors. Published by ESG (www.electrochemsci.org). This article is an open access article distributed under the terms and conditions of the Creative Commons Attribution license (http://creativecommons.org/licenses/by/4.0/). 